УДК 547.917:547.918

\title{
ИЗУЧЕНИЕ СТЕРОИДНЫХ ГЛИКОЗИДОВ ЯКОРЦЕВ СТЕЛЮЩИХСЯ, ПРОИЗРАСТАЮЩИХ В АЗЕРБАЙДЖАНЕ
}

\author{
(C) Г.Б. Искендеров, К.Ф. Гусейнгулиева* \\ Азербайджанский медицинский университет, ул. Бакиханова, 23, Баку, \\ AZ1022 (Азербайджан), e-mail: k-f-h-82@mail.ru
}

С целью поиска источников стероидных гликозидов ряда спиростана нами изучен Tribulus terrestris L. из флоры Азербайджана. Методом последовательной фракционной экстракции с последующим хроматографированием на колонке с силикагелем L из надземной части растения выделены четыре индивидуальных стероидных гликозида, обозначенных по мере увеличения их полярности гликозидами $\mathbf{A}, \mathbf{B}, \mathbf{C}, \mathbf{D}$. Установлены химический состав, молекулярная масса, температура плавления, удельное вращение всех гликозидов. Для выяснения химической природы они подвергались кислотному гидролизу, после соответствующей обработки выделены агликоны в индивидуальном виде, а также изучены моносахариды, входящие в состав углеводной цепи. Идентификация агликонов осуществлена на основании физико-химических констант, сравнения ИК-спектров, хроматографической подвижности в различных системах растворителей и отсутствия депрессии температуры плавления смешанной пробы с подлинными образцами. В жидкой фазе гидролизата методом хроматографии установлено наличие отдельных моносахаридов. На основании экспериментов гликозид А идентифицирован как триллин, гликозид В - монозид рускогенина (3-O- $\alpha$-L-рамнопиранозид), гликозид $\mathbf{C}$ - диосцин (триозид диосгенина), а гликозид $\mathbf{D}$ - диосцинин (тетраозид диосгенина). Монозид рускогенина и диосцинин впервые выделены из якорцев стелющихся. Водорастворимый гликозид диосцинин рекомендуется как исходное вещество для производства высокоэффективного противосклеротического препарата диоспонина.

Ключевые слова: Tribulus terrestris L., стероидные гликозиды, триллин, монозид рускогенина, диосцин, диосцинин.

\section{Введение}

Стероидные гликозиды ряда спиростана обладают широким спектром фармакологического действия $[1,2]$, а стероидные агликоны являются ценным, надежным и доступным сырьем для синтеза гормональных препаратов $[3,4]$. Поэтому изыскание растений, содержащих стероидные гликозиды, а также изучение их индивидуальных компонентов остается актуальным. Одним из таких растений являются якорцы стелющиеся Tribulus terrestris L., широко распространенные на территории Азербайджана и считающиеся сорняком [5].

Якорцы стелющиеся изучаются уже длительное время в основном на содержание стероидных сапогенинов [6-12]. Из якорцев стелющихся, произрастающих в различных регионах мира, выделены: диосгенин, дезоксидиосгенин, рускогенин, гитогенин и 25D-спиростан-3,5-диен [6], и кроме этих, еще тигогенин и хлорогенин [7], диосгенин и тигогенин [8], диосгенин, рускогенин и диоксисапогенин неоспирановой структуры $[9]$, диосгенин $[10,11]$. Как выясняется, один только диосгенин найден во всех случаях. Разработан рациональный способ выделения диосгенина из этого растения, за что получено авторское свидетельство [12].

Имеются также работы по изучению нативных стероидных гликозидов [13-15]. Из якорцев стелющихся, произрастающих в Молдове, выделены и изучены триллин, диосгенин-D-глюкозидо-D-глюкозид,

Искендеров Гаибверди Баширович - заведующий кафедрой общей и токсикологической химии, профессор, доктор фармацевтических наук, e-mail: k-f-h-82@mail.ru

Гусейнгулиева Кенуль Фада кызы - ассистент, диссертант кафедры общей и токсикологической химии, e-mail: k-f-h-82@mail.ru диосцин, грациллин, кикуба-сапонин и протодиосцин $[14,15]$, являющиеся гликозидами диосгенина. Сведения о наличии вышеназванных и других гликозидов представлены также в работах [16-18]. Некоторые гликозиды этого растения имеют агликоны ряда спиростана $[19,20]$ и являются монодесмозидами, а некоторые - ряда фуростана с двумя углеводными цепями и относятся к бисдесмозидам $[20,21]$. В Болгарии из якорцев стелющихся изготовлен

\footnotetext{
* Автор, с которым следует вести переписку.
} 
лекарственный препарат трибестан, содержащий в качестве биологически активных веществ стероидные гликозиды ряда фуростана [22] и имеющий другое назначение - для лечения андрологических заболеваний (мужского бесплодия, возрастного андрогенного дефицита, эректильной дисфункции и общего репродуктивного здоровья мужчин), в отличие от ранее предложенных известных препаратов [10] этого растения (трибестрис, якорцен и др.). Из произрастающих в Грузии якорцев стелющихся предложен препарат трибуспонин, содержащий стероидные гликозиды ряда спиростана $[23,24]$ и обладающий противосклеротическим действием, подобно диоспонину и полиспонину, полученным из различных видов диоскореи [25, 26].

Все вышеизложенные факты указывают на перспективность исследования стероидных гликозидов якорцев стелющихся, произрастающих в различных регионах мира, тем более, что химическая природа, содержание и число стероидных гликозидов растений во многих случаях зависят от места их произрастания [16].

Поэтому мы поставили перед собой задачу изучить стероидные гликозиды якорцев стелющихся, произрастающих в Азербайджане.

\section{Экспериментальная часть}

В качестве объекта исследования использовали надземную часть якорцев стелющихся, заготовленную в июле 2013 г. в период плодоношения на территории Бардинского района Азербайджанской Республики. Собранное сырье сушили в хорошо проветриваемом помещении в тени и измельчали до размера частиц 2 мм. Выяснение качественного состава, однородности и индивидуальности стероидных гликозидов проводили хроматографией в тонком слое сорбента на стандартных пластинках «Силуфол» (Чехия) и «Сорбфил» (Россия), в качестве подвижной фазы использовали различные системы: I - хлороформ - метанол - вода (65 : 35 : 10); II - н-бутанол, насыщенный 10\% уксусной кислотой; III - хлороформ - этанол метанол $(4: 1: 1)$. Обнаружение стероидов на хроматограммах производили реакцией Санье [27]. Температуры плавления веществ определены на приборе Кофлера, удельное вращение - на поляриметре марки П-161. ИК-спектры были сняты на спектрометре Spectrum 100 FT-IR Spectrometers (США) в таблетках КBr. Молекулярные массы веществ установлены по масс-спектрам, которые снимались на масс-спектрометре марки VG-7070. Конфигурацию гликозидных связей определяли по правилу Кляйна [28] путем сравнения молекулярных вращений гликозидов, агликонов и соответствующих метильных производных отдельных моносахаридов.

Выделение стероидных гликозидов из одной и той же навески сырья производили способом последовательной фракционной экстракции сначала 95\% этанолом (І фракция), затем 90\% этанолом (II фракция), в конце 50\% этанолом (III фракция). Масса сырья - 1 кг, соотношение сырья и растворителя - $1: 7$ в первый раз, $1: 5$ в последующих, время экстракции - 24 часа при обычной комнатной температуре, число экстракций - 3 для каждой фракции.

Все три спиртовые извлечения всех фракций объединяли в отдельности, спирт упаривали до получения густой массы и подвергали хроматографическому исследованию в тонком слое сорбента в системах I-III. В I фракции оказались менее полярные вещества, состоящие из двух гликозидов - А, В; во II фракции - одно вещество со средней полярностью - гликозид $\mathbf{C}$; в III фракции - более полярные вещества, представленные тремя гликозидами - D, E, F.

После соответствующей очистки от посторонних побочных примесей отдельные фракции подвергали хроматографическому разделению на колонке с силикагелем L, собирая элюаты по 25 мл и контролируя наличие отдельных индивидуальных гликозидов в элюатах методом ТСХ в различных системах. Элюаты одинакового состава объединяли и растворитель отгоняли. Таким образом были получены индивидуальные гликозиды A, B, C, D, E, F. Гликозиды $\mathbf{E}$ и $\mathbf{F}$ не подвергались дальнейшему исследованию из-за малого их количества.

Прежде всего доказана принадлежность выделенных веществ к стероидам ряда спиростана двумя наиболее убедительными способами: реакцией Санье [27] (пятно характерного желтого цвета) и по ИКспектрам [2, 3]. В ИК-спектрах всех гликозидов имеются полосы поглощения, характерные для спирокетальной группы ядра спиростана $\left(850,900,920,970-980 \mathrm{~cm}^{-1}\right)$, причем полоса 900-920 см${ }^{-1}$ указывает на принадлежность веществ к изо- или к 25 R-ряду [29, 30]. В ИК-спектрах веществ проявляются также полосы поглощения: при 3300-3400 см ${ }^{-1}$, характерные для гидроксильных групп; при 1250-1260 см-1, присущие простым эфирным (гликозидным) связям. 
Гликозид А представляет собой белый аморфный порошок, хорошо растворимый в 90-95\% спирте, ацетоне, $н$-бутаноле, насыщенном водой, не растворим в воде, хлороформе, бензоле, этилацетате и разбавленных спиртах. Химический состав $\mathrm{C}_{33} \mathrm{H}_{52} \mathrm{O}_{8}$, мол. масса - 576, т. пл. $-260-262{ }^{\circ} \mathrm{C},[\alpha]_{\mathrm{D}}^{20}-102^{\circ}$ (с 0,08 ; 95\% этанол). Полный кислотный гидролиз приводит к образованию агликона и D-глюкозы. Агликон имеет химический состав $\mathrm{C}_{27} \mathrm{H}_{42} \mathrm{O}_{3}$, мол. масса -414 , т. пл. $-202-204{ }^{\circ} \mathrm{C},[\alpha]_{\mathrm{D}}^{20}-120^{\circ}$ (с 0,1; хлороформ). На основании физико-химических констант, сравнения ИК-спектров, хроматографического поведения и отсутствия депрессии температуры плавления смешанной пробы с эталонным образцом, агликон идентифицирован как диосгенин.

Гликозид $\mathbf{B}$ - белый аморфный порошок, растворимость такая же, как и у гликозида А. Химический состав $\mathrm{C}_{33} \mathrm{H}_{52} \mathrm{O}_{8}$, мол. масса - 576, т. пл. $-272-274^{\circ} \mathrm{C},[\alpha]_{\mathrm{D}}^{20}-108^{\circ}$ (с 0,$05 ; 95 \%$ этанол). При полном кислотном гидролизе образуются агликон и L-рамноза. Химический состав агликона $\mathrm{C}_{27} \mathrm{H}_{42} \mathrm{O}_{4}$, мол. масса 430 , т. пл. $-202-203{ }^{\circ} \mathrm{C},[\alpha]_{\mathrm{D}}^{20}-117^{\circ}$ (с 0,1; хлороформ). По физико-химическим константам, ИК-спектру, хроматографической подвижности и отсутствию депрессии т. пл. смешанной пробы агликон идентифицирован с рускогенином.

Гликозид С - белый аморфный порошок, хорошо растворим в разбавленных спиртах, ацетоне, $\mu$-бутаноле, насыщенном водой, не растворяется в воде и различных органических растворителях. Химический состав $\mathrm{C}_{47} \mathrm{H}_{72} \mathrm{O}_{16}$, мол. масса - 868, т. пл. $-298-300{ }^{\circ} \mathrm{C},[\alpha]_{\mathrm{D}}^{20}-101^{\circ}$ (с 0,$21 ; 90 \%$ этанол). При кислотном гидролизе получается агликон, а в качестве моносахаридов - D-глюкоза и L-рамноза в соотношении $1: 2$. Сравнением ИК-спектров и физико-химических констант агликон идентифицирован как диосгенин.

Гликозид D - белый аморфный порошок, хорошо растворим в воде, разбавленных спиртах, не растворим в 95\% спирте, органических растворителях. Химический состав $\mathrm{C}_{51} \mathrm{H}_{82} \mathrm{O}_{21}$, мол. масса - 1030 , т. пл. $-208-210^{\circ} \mathrm{C},[\alpha]_{\mathrm{D}}^{20}-88^{\circ}$ (c 0,$11 ; 50 \%$ этанол). Выделенный при полном кислотном гидролизе агликон идентифицирован как диосгенин. В качестве моносахаридов найдены D-глюкоза и L-рамноза в соотношении $2: 2$.

\section{Обсуждение результатов}

Используя последовательную фракционную экстракцию с последующим хроматографированием на колонке с силикагелем L из надземной части якорцев стелющихся, выделили четыре индивидуальных стероидных гликозида, обозначенных по мере увеличения их полярности гликозидами $\mathbf{A}, \mathbf{B}, \mathbf{C}, \mathbf{D}$. Гликозид $\mathbf{A}$ в качестве агликона содержит диосгенин, а в качестве моносахарида - одну молекулу D-глюкозы. Следовательно, гликозид А является монозидом диосгенина. На основании физико-химических свойств и констант нативного гликозида, а также результатов исследования продуктов гидролиза гликозид А идентифицирован как триллин (3-O- $\beta$-D-глюкопиранозид диосгенина), выделенный ранее из этого же растения [15] и других родов [31].

Гликозид В, как показали результаты экспериментов, является монозидом рускогенина и в качестве моносахарида содержит одну молекулу L-рамнозы. Следовательно, гликозид В представляет собой 3-O- $\alpha$ L-рамнопиранозид рускогенина. Гликозид $\mathbf{B}$ не идентичен веществам, выделенным раньше из этого растения, и является, по-видимому, новым гликозидом, по крайней мере, для якорцев.

Гликозид С оказался триозидом диосгенина, в состав углеводной цепи которого входят две молекулы L-рамнозы и одна молекула D-глюкозы. На основании физико-химических данных как самого нативного гликозида, так и продуктов его гидролиза гликозид $\mathbf{C}$ идентифицирован как диосцин, выделенный также из этого растения [14] и других [31].

В результате проводимых многоэтапных экспериментов установили, что гликозид $\mathbf{D}$ является тетраозидом диосгенина, углеводная цепь которого представлена D-глюкозой и L-рамнозой. Сравнивая все физико-химические константы и свойства гликозида $\mathbf{D}$, а также продуктов его гидролиза с литературными данными, можно прийти к заключению, что этот гликозид является диосцинином, впервые выделенным из корневищ Dioscorea [32]. Данный гликозид впервые выделен нами из надземных частей якорцев стелющихся.

Следует отметить, что основные компоненты диоспонина и полиспонина, полученные из корневищ различных видов диоскореи, являются водорастворимыми сапонинами, к числу которых относится диосцинин [32]. Однако производство диоспонина временно приостановлено из-за отсутствия, т.е. истощения 
сырьевой базы - корневищ диоскореи, с условием, что в будущем будет восстановлено производство препарата при наличии достаточного количества сырья [33]. Поэтому нативный гликозид диосцинин, впервые выделенный из якорцев стелющихся, может быть использован в качестве исходного вещества для производства указанного высокоэффективного противосклеротического препарата.

\section{Bblвodbl}

1. Из надземных частей якорцев стелющихся выделены четыре индивидуальных стероидных гликозида: А, В, C, D.

2. Установлено, что гликозид $\mathbf{A}$ является триллином, гликозид $\mathbf{B}$ - монозидом рускогенина, гликозид $\mathbf{C}$ - диосцином, гликозид $\mathbf{D}$ - диосцинином.

3. Монозид рускогенина и диосцинин впервые выделены нами из якорцев стелющихся.

4. Диосцинин может служить исходным сырьем для возобновления производства ценного противосклеротического препарата диоспонина.

\section{Список литературы}

1. Кинтя П.К., Лазурьевский Г.В., Балашова Н.Н., Балашова И.Т. Строение и биологическая активность стероидных гликозидов ряда спиростана и фуростана. Кишинев, 1987. 142 с.

2. Кинтя П.К., Лазурьевский Г.В. Стероидные гликозиды ряда спиростана. Кишинев, 1979. 146 с.

3. амерницкий А.В., Абубакиров Н.К., Горовиц М.Б., Воллернер Ю.Е., Войшвилло Н.Е., Решетова И.Г., Пасешниченко В.А. Химия спиростанолов. М., 1986. 177 с.

4. Азаркова А.Ф., Стихин В.А., Кабанов В.С., Хоциалова Л.И., Майсурадзе Н.И., Черкасов О.Н., Рабинович А.М., Иванов В.Б. Изучение растений родов Dioscorea, Costus и Allium на содержание диосгенина // Химико-фармацевтический журнал. 1984. №2. С. 188-191.

5. Флора Азербайджана. Баку, 1955. С. 74.

6. Kock W.T., Enslin P.R. Chemical investigations of photosensitisation diaseases of domestic animals. Part I. Isolation and characterisation of steroidal sapogenins from Tribulus terrestris // J. S. Afr. Chem. Inst. 1958. Vol. 11, N1. Pp. 33-36.

7. Gheorghiu A., Ionescu-Matiu E. Presence of chlorogenin beside the diosgenin and gitogenin in Tribulus terrestris L. // Ann. pharm. Fr. 1968. Vol. 26, N12. Pp. 745-748.

8. Tomova M.P., Panova D., Vulfson N.S. Steroid saponins and sapogenins IV. Saponines from Tribulus terrestris // Planta Med. 1974. Vol. 25, N3. Pp. 231-237.

9. Искендеров Г.Б. Стероидные сапогенины Tribulus terrestris // Химия природных соединений. 1970. №4. C. 488.

10. Качухашвили T.Н. Якорцы стелющиеся - Tribulus terrestris L. как источник стероидных сапонинов, содержащих диосгенин, и перспектива их использования в медицине // Сборник трудов Тбилисского научноисследовательского химико-фармацевтического института. Тбилиси, 1960. С. 179-189.

11. Качухашвили Т.Н. Диосгенин из якорцев стелющихся (Tribulus terrestris L.), произрастающих в Грузии // Медицинская промышленность СССР. 1965. №3. С. 46-48.

12. А.с. 633528 (СССР). Способ получения диосгенина / Э.Д. Перепелица, П.К. Кинтя, П.Н. Разумовский / 1978.

13. Кинтя П.К., Перепелица Э.Д., Чирва В.Я., Крецу Л.Г. Стероидные сапонины II. Гликозиды Tribulus terrestris // Химия природных соединений. 1972. №4. С. 475-477.

14. Перепелица Э.Д., Кинтя П.К. Диосцин - стероидный гликозид из Tribulus terrestris // Известия АН Молдов. ССР. Сер. биол. и хим. наук. 1974. №6. С. 76-80.

15. Перепелица Э.Д., Кинтя П.К. Химическое изучение стероидных гликозидов Tribulus terrestris IV. Стероидные сапонины // Химия природных соединений. 1975. №2. С. 260-261.

16. Dinchev D., Janda B., Evstatieva L., Oleszek W., Aslani M.R., Kostova I. Distribution of steroidal saponins in Tribulus terrestris from different geographical regions // Phytochemistry. 2008. Vol. 69, N1. Pp. 176-186.

17. Huang J.W., Tan C.H., Jiang S.H., Zhu D.Y. Terrestrinins A and B, two new steroidal saponins from Tribulus terrestris // J. Asian. Nat. Prod. Res. 2003. Vol. 5, N4. Pp. 285-290.

18. Kang L.P., Wu K.L., Yu H.S., Pang X., Liu J., Han L.F., Zhang J., Zhao Y., Xiong C.Q., Song X.B., Liu C., Cong Y.W., Ma B.P. Steroidal saponins from Tribulus terrestris // Phytochemistry. 2014. Vol. 107, N11. Pp. 182-189.

19. Liu T., Chen G., Yi G.Q., Xu J.K., Zhang T.L., Hua H.M., Pei Y.H. Two new steroidal saponins from Tribulus terrestris L. // J. Asian Nat. Prod. Res. 2010. Vol. 12, N1. Pp. 30-35.

20. Zhang J.D., Xu Z., Cao Y.B., Chen H.S., Yan L., An M.M., Gao P.H., Wang Y., Jia X.M., Jiang Y.Y. Antifungal activies and action mechanisms of compounds from Tribulus terrestris L. // J. Ethnopharmacol. 2006. Vol. 103, N1. Pp. 76-84.

21. Su L., Chen G., Feng S.G., Wang W., Li Z.F., Chen H., Liu Y.X., Pei Y.H. Steroidal saponins from Tribulus terrestris // Steroids. 2009. Vol. 74, N4-5. Pp. 399-403. 
22. Ниткин Д.М., Севастьянов Н.С., Гринюк Н.К. Применение препарата Трибестана в лечении основных проблем мужского репродуктивного здоровья // Репродуктивное здоровье. Восточная Европа. 2012. №1 (19). C. $136-143$.

23. Кемертелидзе Э.П., Пхеидзе Т.А., Качухашвили Т.Н. Новый антисклеротический препарат трибуспонин // Химико-фармацевтический журнал. 1982. №1. С. 119-122.

24. Умикашвили Р.С. Фармакологическое исследование сапонинов из якорцев стелющихся - трибуспонина : автореф. дис. ... канд. мед. наук. Тбилиси, 1973. 27 с.

25. Соколова Л.Н., Киченко В.И., Ростоцкий Б.К., Губина Г.П. Диоспонин - новое лекарственное средство для лечения больных атеросклерозом // Медицинская промышленность СССР. 1961. №7. С. 43-45.

26. Лесков А.И., Мартынова Р.Г., Соколов С.Я. Полиспонин - новый лечебный препарат антисклеротического действия // Химико-фармацевтический журнал. 1976. №1. С. 147-150.

27. Sannie Ch., Lapin H. Recherches sur les sapogenines a noyau sterolique. Identification les genines sur de petites quantites de plantes // Bull. Soc. Chim. France. 1952. N11-12. P. 1080.

28. Klyne W. Optical Rotation, in Braude E.A. and Nachod F.C. Determination of Organic Structures by Physical Methods // Academic Press. 1955. Vol. 1. Pp. 73-130.

29. Гвазава Л.Н., Киколадзе В.С. Стероидные сапогенины Polygonatum polyanthemum и P. glaberrimum // Химия природных соединений. 2012. №5. С. 811-812.

30. Бенидзе М.М., Схиртладзе А.В., Кемертелидзе Э.П. Стероидные соединения стеблей Yисca gloriosa // Химия природных соединений. 2012. №3. С. 464-465.

31. Гвазава Л.Н., Киколадзе В.С. Стероидные сапонины из корневищ Polygonatum polyanthemum // Химия природных соединений. 2013. №1. С. 152-153.

32. Мадаева О.С., Рыжкова В.К., Панина В.В. Сапонины Dioscorea polystachya XIV. Диосцинин // Химия природных соединений. 1967. №3. С. 155-158.

33. Шретер А.И., Задорожный А.М. Итоги работ ВИЛР по созданию новых лечебных препаратов растительного происхождения // Растительные ресурсы. 1982. №4. С. 539-547.

Поступило в редакиию 23 января 2016 г.

После переработки 20 февраля 2016 г.

Iskenderov G.B., Huseynguliyeva K.F.* INVESTIGATION OF STEROID GLYCOSIDES TRIBULUS TERRESTRIS L., GROWING IN AZERBAIJAN

Azerbaijan Medical University, ul. Bakikhanova, 23, Baku, Az 1022 (Azerbaijan), e-mail: k-f-h-82@mail.ru

With purpose to search sources of steroid glycosides of the spirostan series we investigated Tribulus terrestris L. in the Azerbaijan flora. By the sequential fractional extraction method, followed column chromatography with silica gel L from the aerial part of plant were isolated four individual steroid glycosides named with increasing of their polarity as glycosides $\mathbf{A}, \mathbf{B}$, C, D. Were established chemical structure, molecular weight, melting temperature, specific rotation of all glycosides. In order to determine the chemical nature, they were hydrolyzed in acidic media. Aglicones were isolated in individual form after appropriate processing, and also investigated monosaccharides, included in the carbon chain. Identification of aglycones performed on the basis of physico-chemical constants, comparison of the IR spectra, chromatographic mobility in various solvent systems and absence of depression of melting point of the mixed sample with authentic samples. In the liquid phase of hydrolysate were established the presence of individual monosaccharides by chromatography method. On the basis of experiments glycoside A was identified as trillin, glycoside B - ruskogenin monoside (3-O- $\alpha$-L-ramnopyranoside), glycoside $\mathbf{C}-$ dioscin (diosgenin trioside) and glycoside $\mathbf{D}$ - dioscinin (diosgenin tetraoside). Ruskogenin monoside and dioscinin were first isolated from Tribulus terrestris. Water-soluble glycoside dioscinin is recommended as an initial substance for the production of highly efficient antisclerotic drug - diosponin.

Keywords: Tribulus terrestris L., steroid glycosides, trillin, ruskogenin monoside, dioscin, dioscinin.

\footnotetext{
${ }^{*}$ Corresponding author.
} 


\section{References}

1. Kintia P.K., Lazur'evskii G.V., Balashova N.N., Balashova I.T. Stroenie i biologicheskaia aktivnost' steroidnykh glikozidov riada spirostana i furostana. [The structure and biological activity of a number of steroidal glycosides and spirostana furostana]. Kishinev, 1987, 142 p. (in Russ.).

2. Kintia P.K., Lazur'evskii G.V. Steroidnye glikozidy riada spirostana. [Steroid glycosides number spirostana]. Kishinev, 1979, 146 p. (in Russ.).

3. Kamernitskii A.V., Abubakirov N.K., Gorovits M.B., Vollerner Iu.E., Voishvillo N.E., Reshetova I.G., Paseshnichenko V.A. Khimiia spirostanolov. [Chemistry spirostanolov]. Moskva, 1986, 177 p. (in Russ.).

4. Azarkova A.F., Stikhin V.A., Kabanov V.S., Khotsialova L.I., Maisuradze N.I., Cherkasov O.N., Rabinovich A.M., Ivanov V.B. Khimiko-farmatsevticheskii zhurnal, 1984, no. 2, pp. 188-191. (in Russ.).

5. Flora Azerbaidzhana. [Flora of Azerbaijan]. Baku, 1955, p. 74. (in Russ.).

6. Kock W.T., Enslin P.R. J. S. Afr. Chem. Inst. 1958, vol. 11, no. 1, pp. 33-36.

7. Gheorghiu A., Ionescu-Matiu E. Ann. pharm. Fr. 1968, vol. 26, no. 12, pp. 745-748.

8. Tomova M.P., Panova D., Vulfson N.S. Planta Med. 1974, vol. 25, no. 3, pp. 231-237.

9. Iskenderov G.B. Khimiia prirodnykh soedinenii. 1970, no. 4, p. 488. (in Russ).

10. Kachukhashvili T.N. Sbornik trudov Tbilisskogo nauchno- icsledovatel'skogo khimiko-farmatsevticheskogo instituta. [Proceedings of Tbilisi Scientific Research Chemical-Pharmaceutical Institute]. Tbilisi, 1960, pp. 179-189. (in Russ).

11. Kachukhashvili T.N. Meditsinskaia promyshlennost' SSSR, 1965, no. 3, pp. 46-48. (in Russ).

12. Patent 633528 (USSR). 1978. (in Russ).

13. Kintia P.K., Perepelitsa E.D., Chirva V.Ia., Kretsu L.G. Khimiia prirodnykh soedinenii, 1972, no. 4, pp. $475-477$. (in Russ).

14. Perepelitsa E.D., Kintia P.K. Izvestiia AN Moldov. SSR. Ser. biol. i khim. nauk. 1974, no. 6, pp. 76-80. (in Russ).

15. Perepelitsa E.D., Kintia P.K. Khimiia prirodnykh soedinenii, 1975, no. 2, pp. 260-261. (in Russ).

16. Dinchev D., Janda B., Evstatieva L., Oleszek W., Aslani M.R., Kostova I. Phytochemistry, 2008, vol. 69, no. 1, pp. $176-186$.

17. Huang J.W., Tan C.H., Jiang S.H., Zhu D.Y. J. Asian. Nat. Prod. Res. 2003, vol. 5, no. 4, pp. $285-290$.

18. Kang L.P., Wu K.L., Yu H.S., Pang X., Liu J., Han L.F., Zhang J., Zhao Y., Xiong C.Q., Song X.B., Liu C., Cong Y.W., Ma B.P. Phytochemistry, 2014, vol. 107, no. 11, pp. 182-189.

19. Liu T., Chen G., Yi G.Q., Xu J.K., Zhang T.L., Hua H.M., Pei Y.H. J. Asian Nat. Prod. Res. 2010, vol. 12 , no. 1. pp. $30-35$.

20. Zhang J.D., Xu Z., Cao Y.B., Chen H.S., Yan L., An M.M., Gao P.H., Wang Y., Jia X.M., Jiang Y.Y. J. Ethnopharmacol, 2006, vol. 103, no. 1, pp. 76-84.

21. Su L., Chen G., Feng S.G., Wang W., Li Z.F., Chen H., Liu Y.X., Pei Y.H. Steroids, 2009, vol. 74, no. 4-5, pp. $399-403$.

22. Nitkin D.M., Sevast'ianov N.S., Griniuk N.K. Reproduktivnoe zdorov'e. Vostochnaia Evropa. 2012, no. 1 (19), pp. 136-143. (in Russ.)

23. Kemertelidze E.P., Pkheidze T.A., Kachukhashvili T.N. Khimiko-farmatsevticheskii zhurnal, 1982, no. 1, pp. 119122. (in Russ.).

24. Umikashvili R.S. Farmakologicheskoe issledovanie saponinov iz iakortsev steliushchikhsia - tribusponina : avtoref. dis. ... kand. med. nauk. [Pharmacological Study of saponins from Tribulus terrestris - Tribusponin: Abstract. Dis. .... Candidate of Medical Sciences]. Tbilisi, 1973, 27 p. (in Russ.).

25. Sokolova L.N., Kichenko V.I., Rostotskii B.K., Gubina G.P. Meditsinskaia promyshlennost' SSSR. 1961, no. 7, pp. 43-45. (in Russ.).

26. Leskov A.I., Martynova R.G., Sokolov S.Ia. Khimiko-farmatsevticheskii zhurnal, 1976, no. 1, pp. 147-150. (in Russ.).

27. Sannie Ch., Lapin H. Bull. Soc. Chim. France. 1952, no. 11-12, p. 1080.

28. Klyne W. Optical Rotation, in Braude E.A. and Nachod F.C. Academic Press. 1955, vol. 1, pp. 73-130.

29. Gvazava L.N., Kikoladze V.S. Khimiia prirodnykh soedinenii, 2012, no. 5, pp. 811-812. (in Russ.).

30. Benidze M.M., Skhirtladze A.V., Kemertelidze E.P. Khimiia prirodnykh soedinenii, 2012, no. 3, pp. 464-465. (in Russ.).

31. Gvazava L.N., Kikoladze V.S. Khimiia prirodnykh soedinenii, 2013, no. 1, pp. 152-153. (in Russ.).

32. Madaeva O.S., Ryzhkova V.K., Panina V.V. Khimiia prirodnykh soedinenii, 1967, no. 3, pp. 155-158. (in Russ.).

33. Shreter A.I., Zadorozhnyi A.M. Rastitel'nye resursy, 1982, no. 4, pp. 539-547. (in Russ.).

Received January 23, 2016

Revised February 20, 2016 